\title{
Milt Production in the Japanese Eel Anguilla japonica Induced by Repeated Injections of Human Chorionic Gonadotropin
}

\author{
Hiromi Ohta, ${ }^{* 1, \dagger}$ Hirohiko Kagawa, ${ }^{* 1}$ Hideki Tanaka, ${ }^{* 1}$ \\ Koichi Okuzawa, ${ }^{* 1}$ and Keiji Hirose*2 \\ ${ }^{*}$ National Research Institute of Aquaculture, Nansei, Mie 516-01, Japan \\ *2National Research Institute of Fisheries Science, Yokohama, \\ Kanagawa 236, Japan
}

(Received May 12, 1995)

\begin{abstract}
Sexually immature male eels ( $253 \mathrm{~g}$ average body weight), reared in sea water at $20^{\circ} \mathrm{C}$, were injected weekly (14 times in total) with human chorionic gonadotropin (HCG) at a concentration of 250 or $750 \mathrm{IU} /$ fish/week. Changes of the milt weight and milt quality were examined two days after each injection. Some of the treated males of both the $250 \mathrm{IU}$ and $750 \mathrm{IU}$ groups spermiated after the 5th injection, and most males spermiated after the 6 th injection. In the $250 \mathrm{IU}$ group, the milt weight gradually increased with increase in the repetitions of injection. It became constant $(1-2 \mathrm{~g})$ during the period of the 11th-13th injection, and reached $4.0 \mathrm{~g}$ after the 14th injection. Acquisition of potential for sperm motility was attained during the period of the 7th-9th injections and the percent motility of spermatozoa at $15 \mathrm{sec}$ after dilution with $450 \mathrm{mM} \mathrm{NaCl}$ remained at approximately $70 \%$ until after the 14th injection. Milt $\mathrm{pH}(8.1-8.2)$ during the period of the 7th-9th injection was significantly higher than the 10th-11th injection period. Serum 17,20 $\beta$-dihydroxy-4-pregnen-3-one levels in the males of both groups remained low $(0.1-0.2 \mathrm{ng} / \mathrm{ml})$ throughout the experiment, although they were significantly higher than the saline control levels $(0.05-0.08 \mathrm{ng} / \mathrm{ml})$. In the $750 \mathrm{IU}$ group, there was a marked difference in milt weight between individual males. The mean total milt weight throughout the experiment per fish of the $250 \mathrm{IU}$ group was $9.4 \mathrm{~g}$, and that of the $750 \mathrm{IU}$ group was $6.1 \mathrm{~g}$. The results indicate that repeated weekly injections of HCG at $250 \mathrm{IU} /$ fish (about $1 \mathrm{IU} / \mathrm{gBW}$ ) over 10 weeks is efficient for the artificial maturation of immature male eels.
\end{abstract}

Key words: artificial maturation, spermatogenesis, spermiation, sperm motility, Japanese eel

Human chorionic gonadotropin (HCG) injections are effective in inducing spermatogenesis and spermiation in many species of teleost including eels. ${ }^{1-8)}$ Oogami and Iizuka ${ }^{9)}$ first succeeded in the artificial maturation of the cultivated male Japanese eel Anguilla japonica by repeated injections of Synahorin, a mixture of HCG and the anterior lobe of mammal pituitary. Recently, HCG has been exclusively used to induce maturation in male $A$. japoni$c a .^{10-16)}$ In this way, eel spermatozoa can be easily obtained even by a single injection of HCG. ${ }^{14)}$ However, Yamauchi and Yamamoto ${ }^{11)}$ reported that males induced to maturation by HCG injections produced little milt with a high viscosity. They emphasized the need to improve the techniques to induce maturation of male eels.

For the development of the techniques for artificial maturation of the teleost males, detailed information concerning the optimal number of hormone injections and dosages to obtain adequate volumes and high quality milt is essential. Only a few studies have been made on this subject in the eel. This paper reports the effects of up to 14 weekly injections of HCG on the quantity of milt production and the milt quality (sperm motility, spermatocrit, and $\mathrm{pH}$ of the milt) in the Japanese eel.

\section{Materials and Methods}

\section{Fish and Hormonal Treatment}

Thirty-two male eels were used, which were purchased from a commercial eel supplier in May, 1993. Before the experiments, fish were gradually acclimated to sea water over 4 days. During the experiments, they were held without feeding in 1,000 l flow-through seawater aquariums under a natural photoperiod at a temperature of $20^{\circ} \mathrm{C}$. They were weighed 5 days after acclimation to sea water (initial body weight). Mean body weight was $253.2 \pm 2.8 \mathrm{~g}$ ( \pm SEM), ranging from 208 to $278 \mathrm{~g}$. They were randomly divided into four groups: 7 eels as an initial control group, 10 as a 250 IU-HCG group, 7 as a 750 IUHCG group, and 8 as a saline control group. The eels of the latter three groups were marked individually by the pit tag system (Identification Devices, Inc.).

The 250 IU-HCG and the 750 IU-HCG group received intraperitoneal injections of 250 IU HCG ("Gonatropin", Teikoku Zoki Co., Ltd.), or 750 IU HCG dissolved in $0.6 \% \mathrm{NaCl}$ were given once a week. The saline control group received $0.6 \% \mathrm{NaCl}$ injections. On the day of the first injection, the initial control males were killed after collection of the blood from the caudal vasculature of the fish

\footnotetext{
$\dagger$ Correspondence to: Hiromi Ohta, National Research Institute of Aquaculture, Nansei, Mie 516-01, Japan.
} 
by a syringe and needle. The gonads were severed and weighed, and a part of them were fixed in Bouin's solution for routine histological observations. Before the $3 \mathrm{rd}$, 5th, $7 \mathrm{th}, 9 \mathrm{th}, 11 \mathrm{th}$, and 13 th injections (seven days after the 2nd, 4th, 6th, 8th, 10th, and 12th injections, respectively), blood of all HCG-treated and saline control fish was collected in the same way. Serum was separated by centrifugation at $10,000 \mathrm{rpm}$ for $10 \mathrm{~min}$, and stored at $-40^{\circ} \mathrm{C}$ until radioimmunoassay.

Two days after the 14 th weekly injection, all the treated fish were weighed and killed. The gonadosomatic index (GSI) was calculated as total gonad weight/body weight multiplied by 100 .

Before each injection and collection of the milt, fish were anesthetized using 2-phenoxyethanol.

\section{Measurement of Milt Weight}

Two days after each hormonal treatment, expressible milt from treated fish was obtained by the application of gentle pressure on the abdomen. The area around the genital pore was rinsed with distilled water, dried with a soft towel, and milt collected using a pre-weighed Pasteur pipette and small tube. Care was taken to avoid contamination of the milt with sea water or urine.

Weight of the milt used for the measurement of $\mathrm{pH}$ and spermatocrit were calculated from differences in the weight of capillary tubes and Pasteur pipette before and after the measurement. The weight was added to the data of milt weight of individual fish.

\section{Sperm Motility}

Milt was maintained on crushed ice in a cool box until the assessment of sperm motility. Sperm motility (\% motility) was observed by VTR (NV-SX10, Panasonic) through a video camera connected to a light microscope $(\times 200)$. Two $\mu l$ of milt was mixed with two $\mathrm{m} l(\times 1,001)$ of $450 \mathrm{~mm}$ $\mathrm{NaCl}$ buffered with $20 \mathrm{~mm}$ HEPES-NaOH at $\mathrm{pH} 7.5^{17)}$ in a polyethylene tube using a vortex mixer, and $50 \mu \mathrm{l}$ of the mixture was immediately transferred onto a glass slide. Spermatozoa were classed as motile when the sperm head showed forward movement 15 seconds after mixing. Percent motility was determined by assessing motility of at least 50 randomly chosen spermatozoa for each measurement. Measurement of each sample was repeated three times and the data averaged.

\section{Measurement of $\mathrm{pH}$ and Spermatocrit}

Milt $\mathrm{pH}$ was measured with a portable $\mathrm{pH}$ meter (" $\mathrm{B}$ 212', Horiba Co., Ltd.). One drop of milt was placed on the sensor of the $\mathrm{pH}$ meter. Each measurement was completed within about one minute of the collection of the milt from the genital pore. Spermatocrit [(packed cell volume/total milt volume $) \times 100$ ] values were determined for each milt sample by centrifuging the capillary tubes $(12,000 \mathrm{rpm}$ for $15 \mathrm{~min})$.

\section{Radioimmunoassay}

Serum levels of 17,20 $\beta$-dihydroxy-4-pregnen-3-one (DHP) were determined by radioimmunoassay (RIA) following the procedure of Young et al. ${ }^{18)} \mathrm{A}$ nondetectable level of DHP was less than $30 \mathrm{pg} / \mathrm{ml}$.

\section{Statistics}

All data are represented as mean \pm SEM. The paired means were examined by one-way analysis of variance and Bartlett's test for uniformity of variances, and the differences were compared by Duncan's multiple range test, Student's $t$-test, or Cochran-Cox test. A result of $p<0.05$ was considered significant.

\section{Results}

GSI values of the initial control males were $0.13 \pm 0.02 \%$. The testes appeared to be formed of single spermatogonia or clusters of a few spermatogonia indicating that the testes were in early and late multiplication stages as previously observed in the cultivated Japanese eels by Yamamoto et al. ${ }^{19)}$ and Miura et al. ${ }^{14)}$

\section{Milt Production and GSI}

Changes in milt weight in response to weekly injections of HCG are shown in Fig. 1. Total milt weight released from individual fish throughout the experiment is shown in Fig. 2A and the mean of each group in Fig. 2B. Mean GSI value of each group measured at the end of the experiment is also shown in Fig. $2 B$.

In the $250 \mathrm{IU}$ group, 2 out of 10 males spermiated after the 5 th weekly injection (Fig. 1). The milt produced was very little $(0.01 \mathrm{~g}$ each). Milt was obtained from 8 males after the 6 th weekly injection, and the mean quantity was $0.08 \pm 0.02 \mathrm{~g}$. From the 7 th injection on, milt could be collected from 9 males until the end of the experiment, the remaining one did not spermiate throughout the experiment. Milt weight per fish gradually increased with the weekly injections. After the 11th injection, the quantity of milt produced became constant (about 1-2 g) until after the 13 th injection, and reached $3.98 \pm 1.48 \mathrm{~g}$ after the 14 th injection.

In the 750 IU group, 2 out of 7 males spermiated after the 5th weekly injection. Milt was obtained from all 7 males from the 6th injection. Only two males (No. 4 and No. 5 in Fig. 2A-right) produced large amounts of milt. The milt yield of No. 5 became $1.33 \mathrm{~g}$ after the 8 th injec-

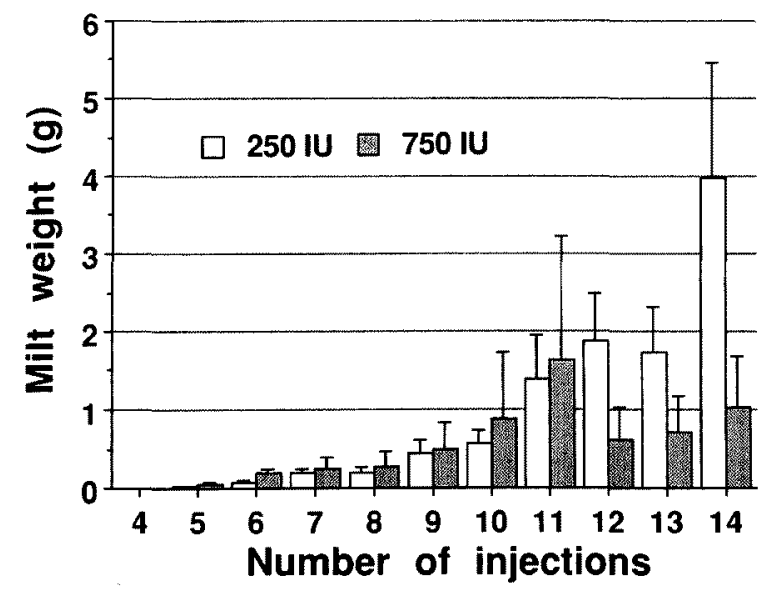

Fig. 1. Changes in expressible milt weight sampled 2 days after weekly injections over a 14 week period.

Data are for males treated with HCG (250 IU/fish/week or 750 IU/fish/week). Vertical lines represent the means \pm SEM. 
tion, increased to $10.49 \mathrm{~g}$ after the 11 th injection, and then remained at about $3 \mathrm{~g}$ until the end of experiment. Male No. 4 gradually increased the milt volume with increasing number of injections, and kept the volume over $1 \mathrm{~g}$ from the 12 th injection to the 14 th injection. The remaining 5 males yielded comparatively large amounts of milt $(0.2-$ $0.4 \mathrm{~g}$ ) during the period of the 5 th to 9 th injection, then the volume gradually decreased. The difference in the total milt weight among individual fish in the 750 IU group was larger than that in the $250 \mathrm{IU}$ group (Fig. 2A). The mean total milt weight in the $250 \mathrm{IU}$ group was $9.42 \pm 3.01 \mathrm{~g}$, and that in the $750 \mathrm{IU}$ group was $6.10 \pm 4.39 \mathrm{~g}$ (Fig. 2B). GSI values of the $250 \mathrm{IU}$ group and $750 \mathrm{IU}$ group were $10.10 \pm 1.22 \%$ and $7.60 \pm 2.03 \%$, respectively (Fig. $2 \mathrm{~B}$ ).

The testes of the saline control males remained immature, and the GSI value was $0.15 \pm 0.01 \%$.

There was no correlation between initial body weight and the total milt weight of each HCG treated male $(r=0.056)$.

\section{Changes of Milt Quality}

Changes of percent motility, spermatocrit, and $\mathrm{pH}$ value of the milt obtained from the males in the $250 \mathrm{IU}$ group are shown in Fig. 3A, B, C, respectively. The percent motility after the 6 th injection was $1.0 \pm 0.4 \%$, increased to $38.8 \pm 8.6 \%$ after the 7 th injection, $37.5 \pm 8.9 \%$
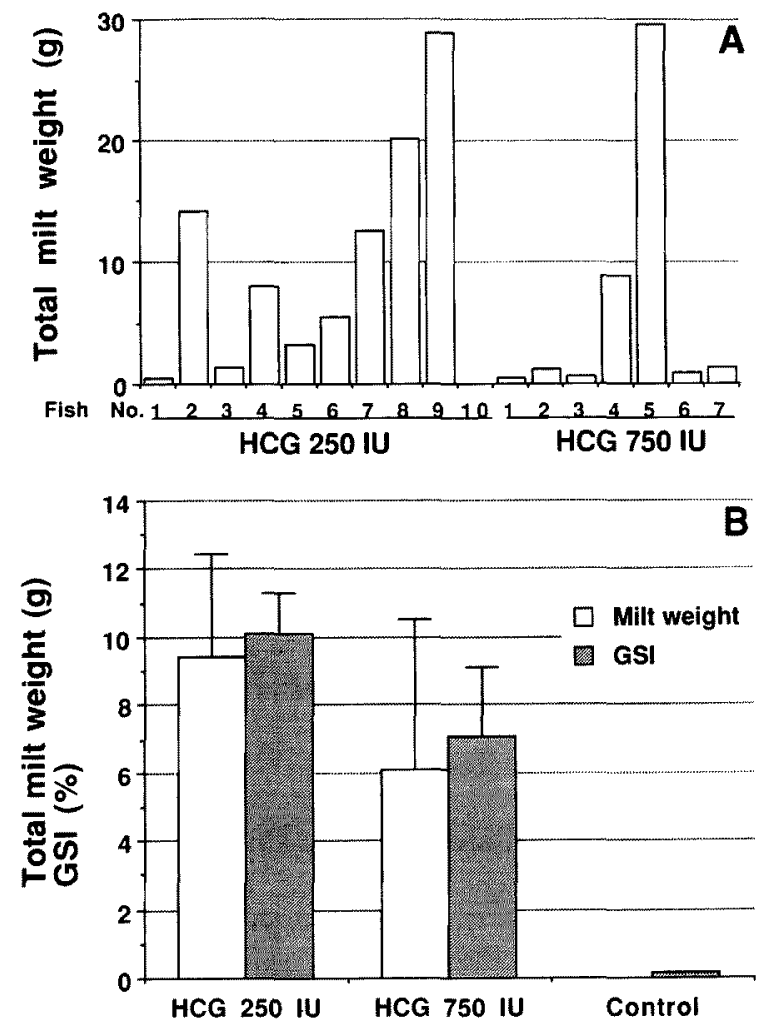

Fig. 2. The total milt weight released per fish over the 14 times weekly injection period of HCG.

A: Bars indicate values for individual fish.

B: The mean \pm SEM of the total milt weight (white bars) in the 250 IU HCG, 750 IU HCG, and saline control groups, and the mean \pm SEM of GSI (shaded bars) of the groups measured at the end of experiment. after the 8 th injection, and reached $74.7 \pm 8.9 \%$ after the 9 th injection. After this, the motility remained at approximately $70 \%$ until the end of the experiment. Spermatocrit values remained at about $70 \%$ throughout the experiment. The mean $\mathrm{pH}$ value of the milt was in the range of 8.09 8.17 during the period of the 7 th-9th injection, then significantly $(p<0.01)$ decreased to 7.86 after the 10th injection. From the 12 th injection the $\mathrm{pH}$ again signif cantly increased $(p<0.05)$ to approximately 8.0 .

Since the males of the $750 \mathrm{IU}$ group yielded smaller quantities of milt, the milt quality could not be measured continuously except for two males (fish No. 4 and No. 5). The parameters of milt quality of these two males showed
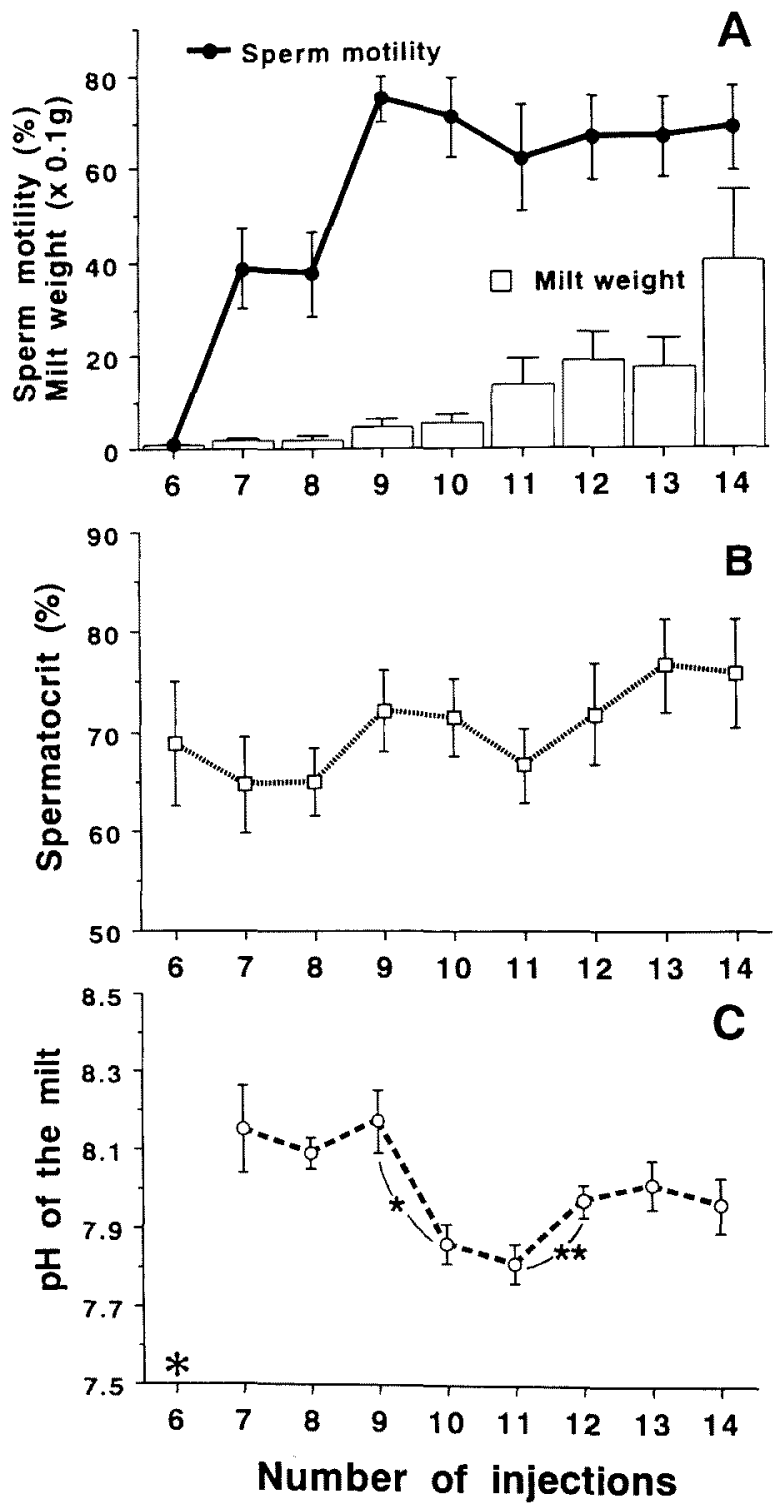

Fig. 3. Changes in sperm motility and milt weight (A), spermatocrit levels (B), and pH of the milt (C) in the 250 IU HCG group from the 6 th to the 14th weekly injection.

The bar graph of milt weight in Fig. 3A is redrawn from the data of Fig. 1. Vertical lines represent the means \pm SEM. The mark "*" in Fig. $3 \mathrm{C}$ indicates the absence of data due to the small amount of milt. The marks " $*$ " and " $\star *$ " represent the significant differences at the $1 \%$ and $5 \%$ levels, respectively. 


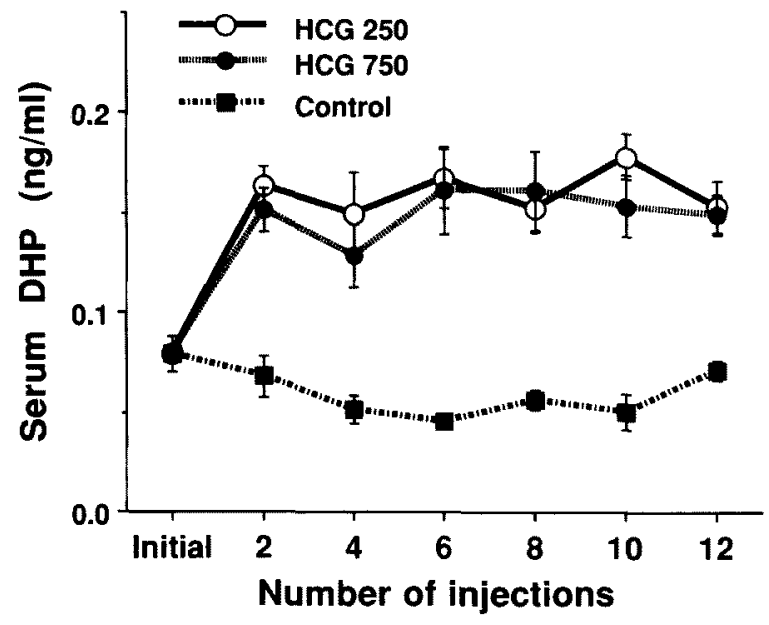

Fig. 4. Changes in serum 17,20 $\beta$-dihydroxy-4-pregnen-3-one (DHP) levels during the 14 weekly injections of $\mathrm{HCG}$.

Blood was collected from the males one week after each injection, that is, just before the $3 \mathrm{rd}$, 5 th, 7 th, $9 \mathrm{th}, 11 \mathrm{th}, 13 \mathrm{th}$ injections. Vertical lines represent the means \pm SEM.

similar trends to those observed in the $250 \mathrm{IU}$ group (data not shown).

\section{Serum DHP Levels}

DHP levels of both the 250 IU and 750 IU groups increased after the second injection compared to the initial level $(p<0.01)$, but maintained low, consistent levels between 0.1 and $0.2 \mathrm{ng} / \mathrm{m} l$ throughout the experiment (Fig. 4).

DHP levels of the saline control group remained between 0.05 and $0.08 \mathrm{ng} / \mathrm{ml}$, which were significantly lower $(p<0.01)$ than both the HCG treated groups throughout the experiment.

\section{Discussion}

In the present study, repeated weekly injections of HCG at $250 \mathrm{IU} /$ fish (approximately $1 \mathrm{IU} / \mathrm{gBW}$ ) to immature male eels, reared in sea water at $20^{\circ} \mathrm{C}$, induced spermiation after the 5th or 6 th injection. After this, the milt volume increased as the number of injections increased and became stable during the 11th and 13th injection period. Sperm motility, examined at two days after each injection, was attained and markedly increased from the 7th-9th injection. These results indicate that the first injection of HCG at $1 \mathrm{IU} / \mathrm{gBW}$ should be carried out at least ten weeks before the anticipated time of fertilization.

In this study, stripping of the milt was performed two days after each injection. Total milt volume per male and the milt quality during one spawning season are known to vary in response to the frequency of milt collection. ${ }^{20,21)}$ For the rainbow trout, Büyükhatipoglu and $\mathrm{Holtz}^{20)}$ reported that about 3 times the milt volume could be obtained in a spawning season by stripping at weekly intervals compared to 4-weekly intervals. Further experiments on the relationship between frequency of stripping and the obtainable milt volume from one male remain to be investigated in the eel.

In male teleosts, 11-KT is a major androgenic steroid, ${ }^{22,23)}$ and DHP is involved in the spermiation in some species. ${ }^{24)}$ Yamauchi and Yamamoto ${ }^{11)}$ reported that male Japanese eels treated with HCG extruded small amounts of milt with high viscosity. Yamauchi ${ }^{13)}$ reported that serum 11-KT remained at high levels, whereas the DHP levels remained extremely low throughout the period of weekly HCG injections. Miura et l. $^{25}$ showed that injections of DHP on these eels, which had received 5 HCG injections, markedly increased the milt volume (to about $2 \mathrm{~m} l$ ) and the percent motility of the spermatozoa (from $20 \%$ to $70 \%$ ). They concluded that the high levels of $11-\mathrm{KT}$ evoked by the HCG injections induced spermatogenesis, and the low levels of DHP synthesis caused unsuccessful spermiation. In the present study, serum DHP levels also remained low throughout the period of HCG injections. However, males gradually increased the milt volume and the percent motility of spermatozoa as the number of the HCG treatment increased. The present results show that repeated weekly injections of HCG over 6 times induce maturation gradually in the male eels, taking about 3-4 weeks. This is in marked contrast to the injections of DHP which induced rapid increases of milt weight and percent motility. 25 )

In salmonids, serum DHP levels show a marked increase at the maturational stage of males (amago salmon, 5-8 $\mathrm{ng} / \mathrm{m} l ;{ }^{26)}$ chum salmon, $10 \mathrm{ng} / \mathrm{m} l ; ;^{27)}$ coho salmon, 30-40 $\mathrm{ng} / \mathrm{m} l{ }^{28)}$ pink salmon, $100 \mathrm{ng} / \mathrm{m} l{ }^{29)}$ Peak levels of marine teleost are known to be generally lower (red seabream, $0.35 \mathrm{ng} / \mathrm{m} l ;^{30)}$ New Zealand snapper, $0.6 \mathrm{ng} / \mathrm{m} l ;^{31)}$ sardine, about $1-2 \mathrm{ng} / \mathrm{m} / ;^{32,33)}$ Japanese flounder, $0.1 \mathrm{ng} /$ $\left.\mathrm{m} \beta^{44}\right)$. The serum DHP levels of eels in the present study $(0.1-0.2 \mathrm{ng} / \mathrm{m} l)$ are similar to those of other marine teleosts, although the eels received repeated HCG treatments. As Matsuyama et al. ${ }^{34)}$ suggested, the blood levels of DHP might not reflect the physiological significance of this steroid. Furthermore, in this study blood samples were collected 7 days after each injection. Since the serum HCG levels peaked 6-12 hours after HCG injections (Ohta and Tanaka, in preparation), and the rapid metabolism and clearance of DHP from the plasma are reported ${ }^{35}$ ) the levels of DHP shown in Fig. 4 may not reflect the crucial changes in response to the HCG injections. Asahina et $a l .^{36-38)}$ reported that spermatozoa of carp, goldfish, and flounder can synthesize 17,20 $\alpha$-dihydroxy-4-pregnen-3one (the isomer of DHP) from $17 \alpha$-hydroxyprogesterone, and blood levels of 17,20 $\alpha$-dihydroxy-4-pregnen-3-one increase to almost the same levels as those of DHP during spawning in the male goldfish. They proposed that $17,20 \alpha-$ dihydroxy-4-pregnen-3-one also plays a role in regulating spermiation in these fishes. We did not measure the levels of this steroid in the present study. Further detailed investigation will be necessary to understand hormonal regulation on maturation in the male Japanese eel.

In salmonids, spermatozoa acquire a capacity for movement during the passage from the testes along the sperm duct. ${ }^{39)}$ High concentrations of $\mathrm{HCO}_{3}$ and higher $\mathrm{pH}(7.8-$ 8.15 ) in the seminal plasma are important factors promoting the potential for motility of the spermatozoa ${ }^{40)}$ In the Japanese eel, injections of DHP induced the acquisition of sperm motility, which was accompanied by an increase in $\mathrm{pH}$ values of the sperm duct. ${ }^{25)}$ When immotile spermatozoa from the eel testes were incubated in an isotonic 
solution containing $20 \mathrm{~mm} \mathrm{NaHCO} 3$ with a high $\mathrm{pH}$ (7.88.2 ) for $20 \mathrm{~min}$, the percent motility increased significantly. ${ }^{41)}$ Also in the present study, $\mathrm{pH}$ values of the milt over the period of initial acquisition of sperm motility (during 7-9 times injection) were significantly higher than those of the later period (10-11 times injection). Unfortunately we could not measure the $\mathrm{pH}$ of the milt with low sperm motility in the early spermiation period (5-6 times injection) because of the small amount of milt. Carp spermatozoa, however, acquire motility with incubation in isotonic solutions with high concentrations of $\mathrm{KCl}$ or $\mathrm{NaCl}$, and this process is not $\mathrm{pH}$ dependent. ${ }^{42)}$ Ohta and Izawa ${ }^{17)}$ showed that the ionic composition, in particular the potassium ion concentration, of the isotonic medium has a marked effect on in vitro preservability of the motility of eel spermatozoa. These results suggest that the ionic constituents of testicular fluid are involved in the acquisition and retention of teleostean sperm motility in addition to the $\mathrm{pH}$ value. It still remains unknown as to which external factors are involved in the acquisition of sperm motility in the eel.

Although most of the males spermiated in response to HCG treatment, there is a large difference in the milt weight between individual males, especially in the $750 \mathrm{IU}$ group. For practical purposes, it is necessary to understand the cause of these differences in the responsiveness to the HCG treatment. We have little data to explain this phenomena. There was no relation between the initial body weight and the milt volume in the present study. Further experiments concerning the effects of various differences, such as the initial developmental stages of the gonad, gonadal ability for steroidogenesis, and metabolizing velocity of $\mathrm{HCG}$, among the males on induced maturity are necessary.

In conclusion, the present study examined the effects of weekly injections of $\mathrm{HCG}$ for 14 weeks on immature male eels reared in sea water at $20^{\circ} \mathrm{C}$, and clarified the following: (1) repeated injections of HCG at 250 IU induced spermiation after 5-6 injections, and the acquisition of sperm motility occurred during the period of the 7th-9th injections; (2) milt volume increased gradually, and became stable after the 11 th injection. An artificially matured female eel produces about $300-400 \mathrm{~g}$ of ripe eggs (Tanaka et al., unpublished data), however, milt obtained by the present method was $1-4 \mathrm{~g}$ per male at most. Further advances in methodology for artificial insemination may be necessary to produce large amounts of fertilized eggs in this species.

Acknowledgments We are very grateful to Dr. T. Miura, Hokkaido University, for his helpful discussion. This work was supported in part by a Grant-in-Aid of the Preceded Research Program provided by the Ministry of Agriculture, Forestry and Fisheries (MAFF), Japan (PRP 9510-1).

\section{References}

1) T. J. Lam: Application of endocrinology to fish culture. Can. J Fish. aquat. Sci., 39, 111-137 (1982).

2) E. M. Donaldson and G. A. Hunter: Induced final maturation, ovulation, and spermiation in cultured fish, in "Fish Physiology" (ed. by W. S. Hoar, D. J. Randall, and E. M. Donaldson), Vol. 9B, Academic Press Inc., New York, 1983, pp. 351-403.

3) B. Boëtius and J. Boëtius: Studies in the European eel, Anguilla anguilla (L.). Experimental induction of the male sexual cycle, its rela- tion to temperature and other factors. Meddelelser fra Danmarks Fiskeri-og Havundersagelser 4, 339-405 (1967).

4) P. R. Todd: Ultrastructure of the spermatozoa and spermiogenesis in New Zealand freshwater eels (Anguillidae). Cell Tissue Res., 171, 221-232 (1976).

5) K. Bieniarz and P. Epler: Investigations on inducing sexual maturity in the male eel Anguilla anguilla L. J. Fish Biol., 10, 555-559 (1977).

6) P. W. Sorensen and H. E. Winn: The induction of maturation and ovulation in American eels, Anguilla rostrata (LeSueur), and the relevance of chemical and visual cues to male spawning behaviour. J. Fish Biol., 25, 261-268 (1984).

7) J. Dollerup and C. M. Graver: Repeated induction of testicular maturation and spermiation, alternating with periods of feeding and growth in silver eels, Anguilla anguilla (L.). Dana, 4, 19-39 (1985).

8) I. A. Khan, E. Lopez, and J. Leloup-Hâtey: Induction of spermatogenesis and spermiation by a single injection of human chorionic gonadotropin in intact and hypophysectomized immature European eel (Anguilla anguilla L.). Gen. Comp. Endocrinol., 68, 91-103 (1987).

9) H. Oogami and S. Iizuka: Induced maturation of Japanese eel by gonadotropin injections. Annual Reports of Shizuoka Pref. Fish. Exp. Stn. 1962, 65-67 (in Japanese).

10) Y. Sugimoto and H. Takahashi: Ultrastructural changes of testicular interstitial cells of silver Japanese eels, Anguilla japonica, treated with human chorionic gonadotropin. Bull. Fac. Fish. Hokkaido Univ., 30, 23-33 (1979).

11) K. Yamauchi and K. Yamamoto: Experiments on artificial maturation and fertilization of the Japanese eel (Anguilla japonica), in "Reproductive Physiology of Fish" (ed. by C. J. Richter and G. J. Th. Goos), Pudoc Press, Wageningen., 1982, pp. 185-189.

12) K. Yamauchi, T. Miura, and Y. Nagahama: Involvement of $17 \alpha, 20 \beta$-dihydroxy-4-pregnen-3-one in the final stage of sperm maturation in male masu salmon, Oncorhynchus masou and Japanese eel, Anguilla japonica, in "Proceedings of the first congress of the Asia and Oceania Society for Comparative Endocrinology (AOSCE)"' (ed. by E. Ohnishi, Y. Nagahama, and H. Ishizaki), Nagoya University Corporation, Printing Section, Nagoya, 1987, pp. 179-180.

13) K. Yamauchi: Studies of gonadal steroids involved in final gonadal maturation in the Japanese eel, Anguilla japonica, a review. Int. Revue ges. Hydrobiol., 75, 859-860 (1990).

14) T. Miura, K. Yamauchi, Y. Nagahama, and H. Takahashi: Induction of spermatogenesis in male Japanese eel, Anguilla japonica, by a single injection of human chorionic gonadotropin. Zool. Sci., 8, 63-73 (1991).

15) J.-C. Gwo, H.-H. Gwo and S.-L. Chang: The spermatozoon of the Japanese eel, Anguilla japonica (Teleostei, Anguilliformes, Anguillidae). J. Submicrosc. Cytol. Pathol., 24, 571-574 (1992).

16) H. Tachiki and T. Nakagawa: Induction of spawning in female cul. tured eel Anguilla japonica. Bull. Aichi Fish. Res. Inst., 1, 79-83 (1993) (in Japanese).

17) H. Ohta and T. Izawa: Diluent for cool storage of the Japanese eel (Anguilla japonica) spermatozoa. Aquaculture, (in press).

18) G. Young, L. W. Crim, H. Kagawa, A. Kambegawa, and Y. Nagahama: Plasma 17 $\alpha, 20 \beta$-dihydroxy-4-pregnen-3-one levels during sexual maturation of amago salmon (Oncorhynchus rhodurus): Correlation with plasma gonadotropin and in vitro production by ovarian follicles. Gen. Comp. Endocrinol., 51, 96-105 (1983).

19) K. Yamamoto, O. Hiroi, T. Hirano, and T. Morioka: Artificial maturation of cultivated male Japanese eels by synahorin injection. Nippon Suisan Gakkaishi, 38, 1083-1090 (1972) (in Japanese).

20) S. Büyükhatipoglu and W. Holtz: Sperm output in rainbow trout (Salmo gairdneri)-effect of age, timing and frequency of stripping and presence of females. Aquaculture, 37, 63-71 (1984).

21) K. R. Munkittrick and R. D. Moccia: Seasonal changes in the quality of rainbow trout (Salmo gairdneri) semen: effect of a delay in stripping on spermatocrit, motility, volume and seminal plasma constituents. Aquaculture, 64, 147-156 (1987).

22) R. Billard, A. Fostier, C. Weil, and B. Breton: Endocrine control 
of spermatogenesis in teleost fish. Can. J. Fish. aquat. Sci., 39, 6579 (1982).

23) A. Fostier, B. Jalabert, R. Billard, B. Breton, and Y. Zohar: The gonadal steroids, in "Fish Physiology" (ed. by W. S. Hoar, D. J. Randall, and E. M. Donaldson), Vol. 9A, Academic Press Inc., New York, 1983, pp. 277-372.

24) Y. Nagahama: Gonadotropin action on gametogenesis and steroidogenesis in teleost gonads. Zool. Sci., 4, 209-222 (1987).

25) T. Miura, K. Yamauchi, H. Takahashi, and Y. Nagahama: Involvement of steroid hormones in gonadotropin-induced testicular maturation in male Japanese eel (Anguilla japonica). Biomed. Res., 12, 241-248 (1991).

26) H. Ueda, G. Young, L. W. Crim, A. Kambegawa, and Y. Nagahama: $17 \alpha, 20 \beta$-dihydroxy-4-pregnen-3-one: plasma levels during sexual maturation and in vitro production by the testes of amago salmon (Oncorhynchus rhodurus) and rainbow trout (Salmo gairdneri). Gen. Comp. Endocrinol, , 51, 106-112 (1983).

27) H. Ueda, O. Hiroi, A. Hara, K. Yamauchi, and Y. Nagahama: Changes in serum concentrations of steroid hormones, thyroxine, and vitellogenin during spawning migration of the chum salmon, Oncorhynchus keta. Gen. Comp. Endocrinol., 53, 203-211 (1984).

28) M. S. Fitzpatrick, G. V. D. Kraak, and C. B. Schreck: Profiles of plasma sex steroids and gonadotropin in coho salmon, Oncorhynchus kisutch, during final maturation. Gen. Comp. Endocrinol., 62, 437-451 (1986).

29) H. M. Dye, J. P. Sumpter, U. H. M. Fagerlund, and E. M. Donaldson: Changes in reproductive parameters during the spawning migration of pink salmon, Oncorhynchus gorbuscha (Walbaum). $J$. Fish Biol., 29, 167-176 (1986).

30) K. Ouchi, S. Adachi, and Y. Nagahama: Changes in plasma levels of steroid hormones during sexual maturation of male red seabream Pagrus major. Nippon Suisan Gakkaishi, 54, 593-597 (1988).

31) J. F. Carragher and N. W. Pankhurst: Plasma levels of sex steroids during sexual maturation of snapper, Pagrus auratus (Sparidae), caught from the wild. Aquaculture, 109, 375-388 (1993).

32) M. Matsuyama, S. Adachi, T. Nagahama, C. Kitajima, and S. Matsuura: Testicular development and serum levels of gonadal steroids during the annual reproductive cycle of captive Japanese sardine. Japan. J. Ichthyol., 37, 381-390 (1991).
33) T. Matsubara, S. Honda, K. Soyano, and T. Wada: Seasonal changes in testicular developmental stages and serum levels of steroid hormones in the rearing male Japanese sardine (Sardinops melanostictus). Bull. Hokkaido Natn. Fish. Res. Inst., 56, 7-16 (1992) (in Japanese).

34) M. Matsuyama, M. Yoneda, H. Takeuchi, H. Kagawa, M. Kashiwagi, K. Tabata, Y. Nagahama, S. Ijiri, S. Adachi, and K. Yamauchi: Diurnal periodicity in testicular activity in the Japanese flounder Paralichthys olivaceus. Fisheries Sci., 61, 17-23 (1995).

35) A. P. Scott and A. V. M. Canario: $17 \alpha, 20 \beta$-dihydroxy-4-pregnen3-one 20-sulphate: a major new metabolite of the teleost oocyte maturation-inducing steroid. Gen. Comp. Endocrinol. 85, 91-100 (1992).

36) K. Asahina, T. Barry, K. Aida, N. Fusetani, and I. Hanyu: Biosynthesis of $17 \alpha, 20 \beta$-dihydroxy-4-pregnen-3-one from $17 \alpha$-hydroxyprogesterone by spermatozoa of the common carp, Cyprinus carpio. J. expl. Zool., 255, 244-249 (1990).

37) K. Asahina, K. Aida, and T. Higashi: Biosynthesis of $17 \alpha, 20 \beta$-dihydroxy-4-pregnen-3-one from 17 $\alpha$-hydroxyprogesterone by goldfish (Carassius auratus) spermatozoa. Zool. Sci., 10, 381-383 (1993).

38) K. Asahina, J. G. Lambert, and H. J. T. Goos: Bioconversion of $17 \alpha$-hydroxy-progesterone into $17 \alpha, 20 \alpha$-dihydroxy-4-pregnen-3one and $17 \alpha, 20 \beta$-dihydroxy-4-pregnen-3-one by flounder (Platichthys flesus) spermatozoa. Zool. Sci., 11, 859-863 (1994).

39) S. Morisawa and M. Morisawa: Acquisition of potential for sperm motility in rainbow trout and chum salmon. J. expl. Biol., 126, 8996 (1986).

40) S. Morisawa and M. Morisawa: Induction of potential for sperm motility by bicarbonate and $\mathrm{pH}$ in rainbow trout and chum salmon. J. expl. Biol., 136, 13-22 (1988).

41) T. Miura, T. Kasugai, Y. Nagahama, and K. Yamauchi: Acquisition of potential for sperm motility in vitro in Japanese eel. Fish eries Sci., 61, 533-534 (1995).

42) C. Redond-Müller, M.-P. Cosson, J. Cosson, and R. Billard: In vitro maturation of the potential for movement of carp spermatozoa. Mol. Reprod. Develop., 29, 259-270 (1991). 